بررسى روايى و پايايى نسخه فارسى بر سشنامه انقام در رانندىى

$$
\text { ، حميل رضا شركاء'، سيد عباس متوليان'، رضوان رجب زاده' }
$$

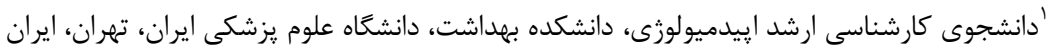

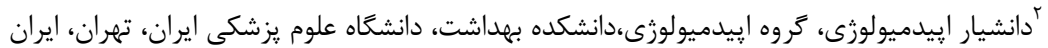

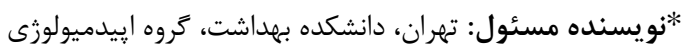
يست الكترونيك: solaymani.m@iums.ac.ir

زمينه و هدف: حوادث جاده اى در ايران اولين علت بار بيماريها مى باشد. راندگى تنها به كار بردن مهارت

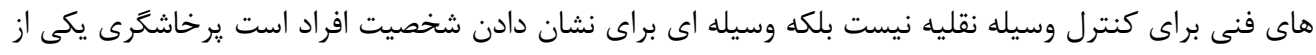

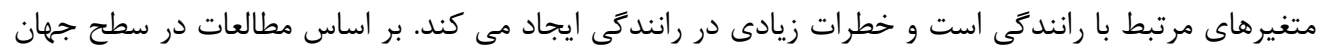

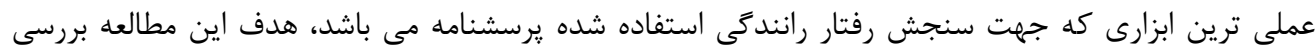

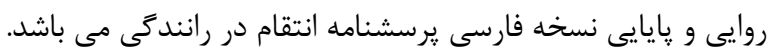

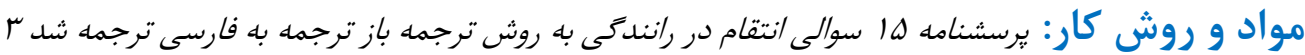

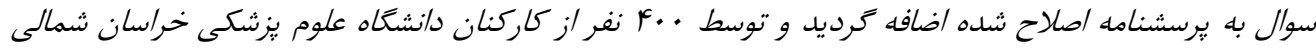

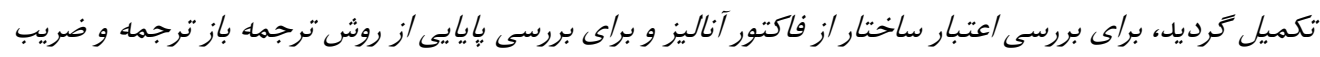

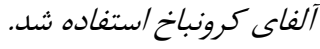

يافته ها: ميانكَين سنى /فراد شركت كننده

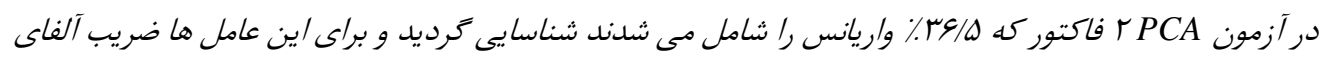

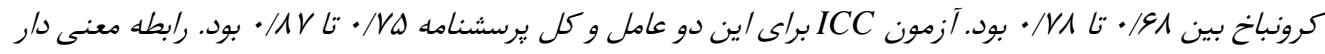
بين نمره انتقام و سن و جنس مشاهده كرديد. نتيجه كيرى: نتايج نشان مى دهد كه نسخه فارسى 11 سوالى DVQ معيار مناسبى براى بررسى رفتار انتقام جويانه راندكى مى باشد. وازه هاى كليدى: برسشنامه انتقام در راندكى، مطالعات روايى، بايايى. 
شخصيت افراد است يس بنابراين رانندكى مى تواند وسيله اي براى ابراز لايه هاى ينهان شخصيت، نخرش و انگَيزه

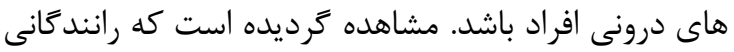

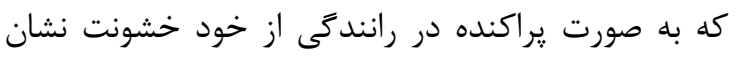
مى دهند در مجموع به صورت متناوب خشونت را به ردان عنوان يكى از لايه هاى ينهان شخصيت خود بروز إنى

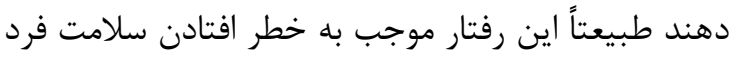

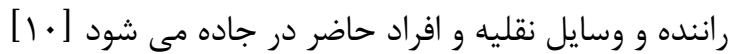
از جمله متغيرهاى مرتبط با رانندكى يرخاشكَىى است،

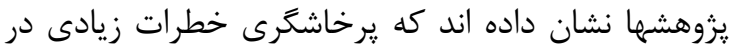

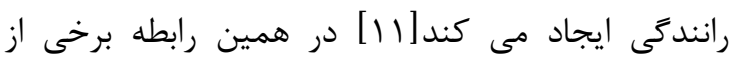
نظريه يردازان دو نوع يرخاشكرى را از يكديكر متمايز

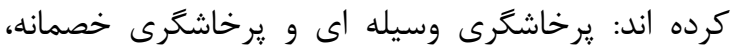

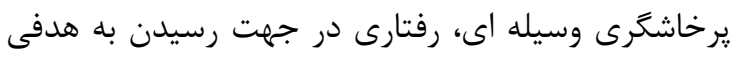

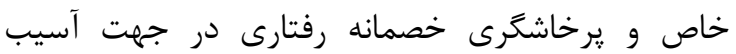

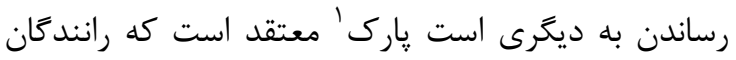
مهاجم در راندگى خود بيشتر دركير يرخاشكرى وسيله

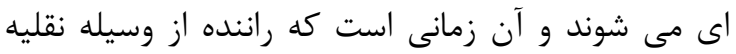

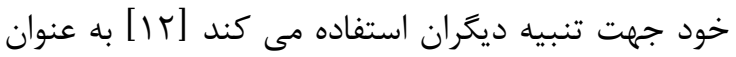

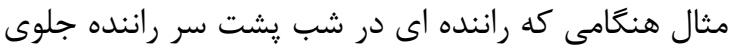

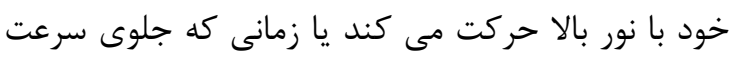

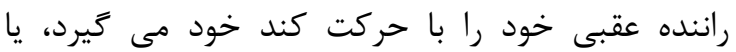
هنغامى كه با سرعت بالا و با بوقهاى ممتد قصد تنبيه ساير راندكان را دارد، از يرخاشكرى وسيله الى استفاده

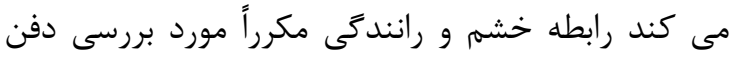

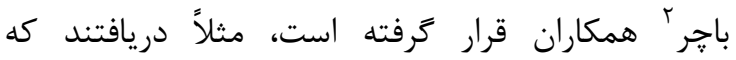

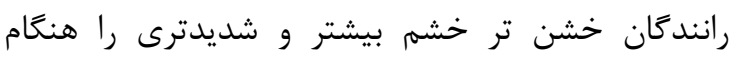

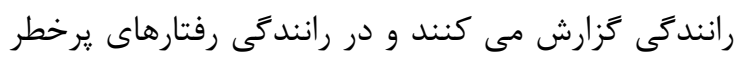

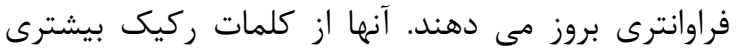
استفاده مى كنند و همجنين سريعتر رانندگى مى كنى دهند

در يك گروه اجتماعى هنكامى كه يكى از اعضا از قوانين تخطى مى كند ساير اعضا خشمخين مى شوند و براى

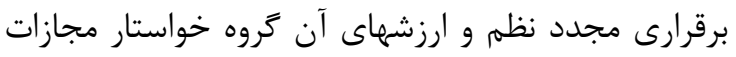

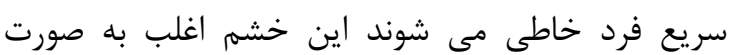

\section{1-Park}

2-Deffenbacher

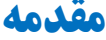

حوادث جاده اى هشتمين علت مرگ در تمام گروه هاى

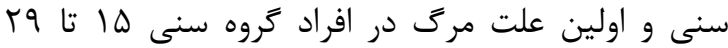
سال در سرتاسر جهان مى باشد كه موجب از دست رفت رداد تعداد زيادى از نيروهاى فعال جوامع مى كَ كردد سالانه

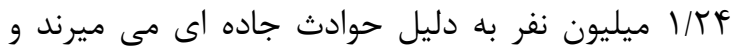

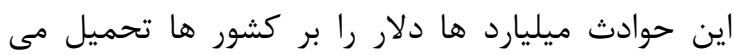

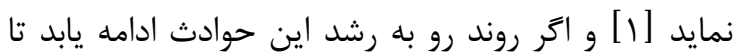

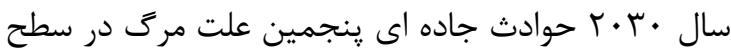

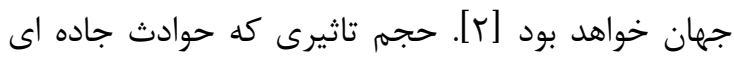

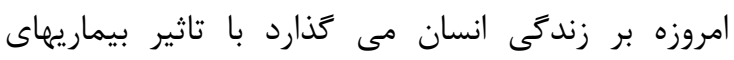
واكيردارى مثل مالاريا در كذشته برابر است [ب]ـ بنا بر ززارش سازمان يزشكى قانونى كشور در سال سوها

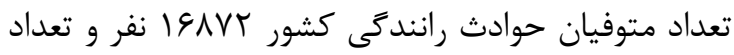

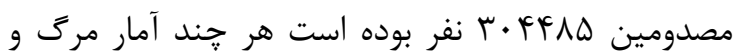
مصدومين در جند سال كذشته رو به كاهش بوده است و

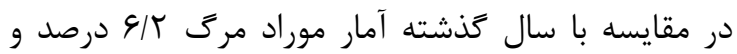
آمار مصدومين ب/ ب/ درصد كاهش يافته است با اين حال روزانه \&† نفر به دليل حوادث رانندكى در سراسر كشور

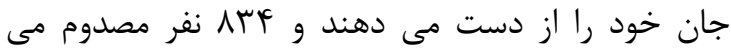

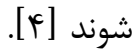

مطالعات متعددى با هدف تعيين رابطه عليتى و شناسايى

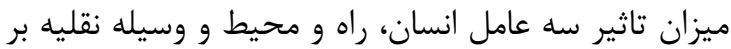
تصادفات انجام شده است و طبق نتايج آن فاكتورهاى

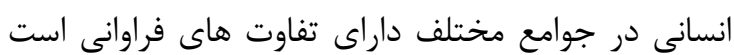
اما اشتراك تمامى آنها بيشتر بودن فاكتور عامل انسانى دانى دانى

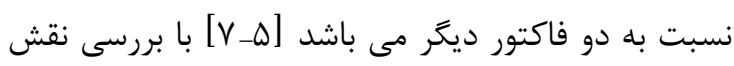
غير قابل انكار انسان در زنجيره يِيجيده رخداد هاى مناى منجر به تصادف، يك اقدام ارزشمند در ايمنى حمل و نقل شناسايى هر קه بيشتر اين عامل مهم مى باشد در بررسى

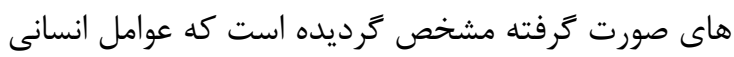
عامل •9 تا 90\% كل مجموعه عوامل ايجاد كننده

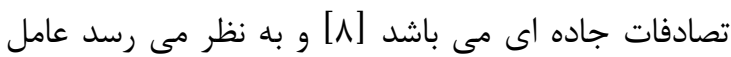
اصلى سه تصادف از هر ينج تصادف مرتبط با رفتار راننده باشد [9] رانندگى تنها به كار بردن مهارت هاى فنى براى كنترل

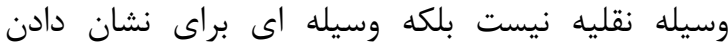


مطالعه بررسى روايى و يايايى نسخه فارسى يرسشنامه انتقام در راندگى مى بـ باشد.

\section{روش كار}

اين مطالعه به صورت مقطعى مصاحبه و تكميل يرسشنامه

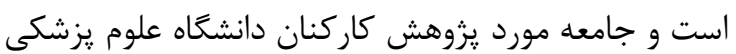
خراسان شمالى مى باشند در اين مطالعه از روش تركيبى

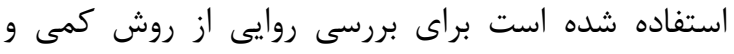

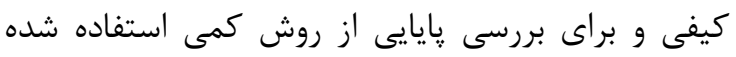

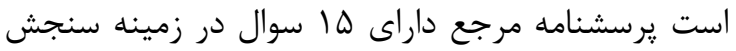
انتقام در راندكان مى باشد. روش نمونه كيرى در اين درائ مطالعه خوشه اى و نمونه كيرى آسان مى باش باشد در ابتدان ليست تمامى واحد هاى تحت يوشش دانشخاه علوم

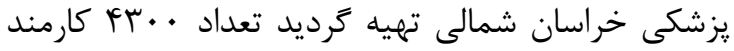

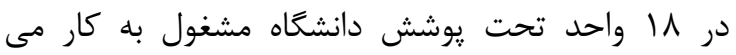
باشند از اين 1 ا واحد تعداد 9 واحد (به عنوان خوشه) به داحنه روش نمونه كيرى تصادفى ساده انتخاب گرديد با وجود مشخص بودن جهار جوب نمونه گيرى و وجود ليست كاركنان شاغل در هر واحد به دليل اينكه يكى از معيار هاى ورود افراد به مطالعه داشتن حداقل سه سال سابقه رانندگى مى باشد و مشخص نبودن سابقه رانندگى افراد

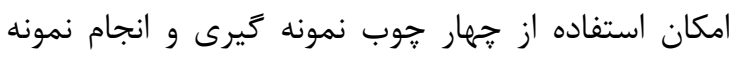
كيرى سيستماتيك وجود نداشت و از نمونه كيرى آسان براى انتخاب افراد مورد مطالعه در داخل هر خوشه استفاده كرديد، در داخل هر خوشه به هأَ نفر از كاركنان جهت انجام مطالعه يرسشنامه تحويل داده شد و در در در صورت عدم تمايل فرد براى شركت در مطالعه به فرد در دسترس ديگر اين يرسشنامه ارائه كرديد. يرسشنامه مورد

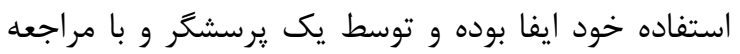

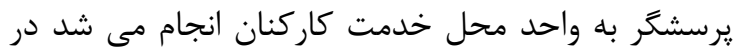
هر واحد يكى از كاركنان آن واحد كه تمامى كاركنان را

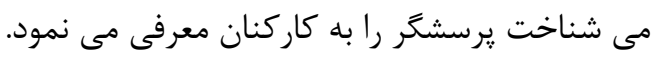
به عنوان اولين قدم در اجراى مطالعه حاضر و انجام مرحله روايى زبان شناختى، نسخه اصلى يرسشنامه با استفاده از

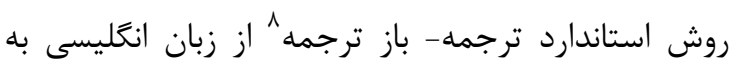

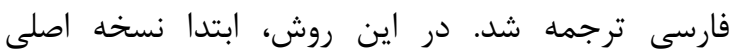

\section{8- Backward-Forward}

درخواست انتقام نمايان مى گردد در رانندگى نيز تخلفات رانندكان مانند راندكى كند در خط سرعت، راهنماى

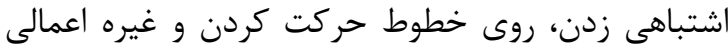

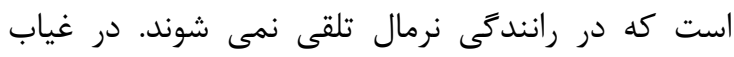

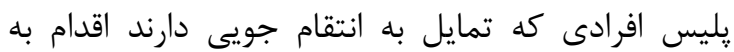
مجازات فرد خاطى مى نمايند و عقيده دارند فرد خاطى ديى داري

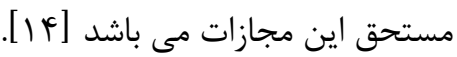

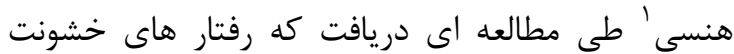
آميز راندكَى در راندكانى كه داراى امتياز منفى به دليل تخلفات و رفتار هاى تهاجمى بوده اند بيشتر است و

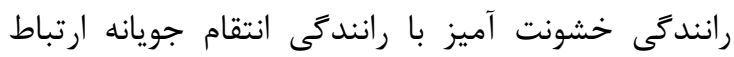

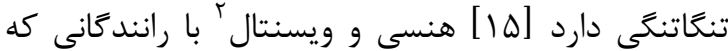
در ترافيك سنگين حضور داشتند مصاحبه كردند و مشاهده نمودند كه در اين شرايط رانندكان بيشتر تحريك مى شوند و رفتار هاى خشونت آميزى مانند بوق زدن،

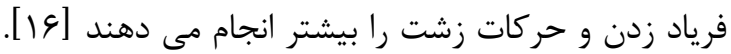

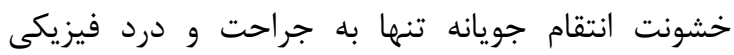
محدود نمى شود بلكه شامل آسيب روحى و تحقير و ودريأه رنجش فرد مقابل مى شود [IV]

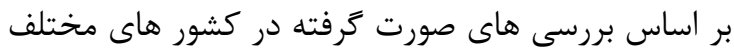

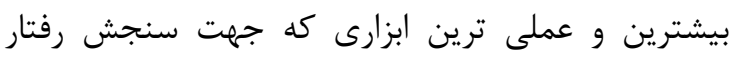

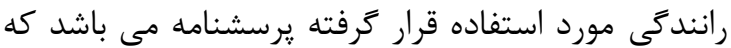

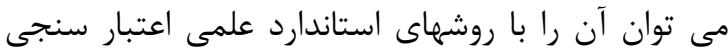

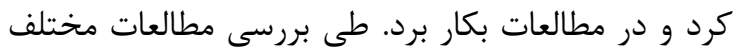

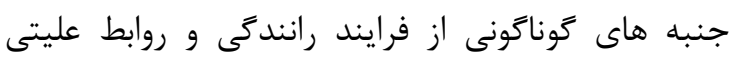
مورد بررسى قرار گرفته است كه از جمله مى توان سنجش رفتار رانندكى به وسيله يرسشنامه استاندارد رفتار

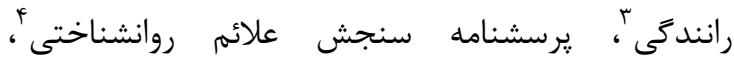

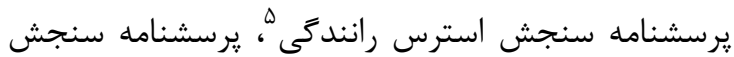

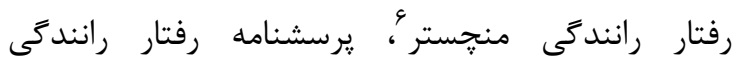

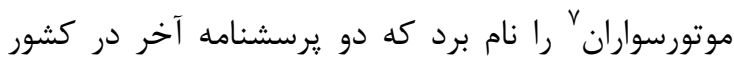

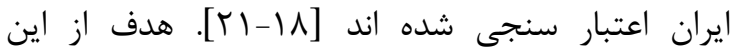

\section{1- Hennessy}

2- Wiesenthal

3- Driver Behavior Questionnaire

4- Brief Symptom Inventory

5- Driver Behavior Inventory

6 -Manchester Driving Behavior Questionnaire 7- Motorcycle Rider Behavior Questionnaire 
هاى مجزا تفكيك نمود) از آزمون كايزر ماير اولكين

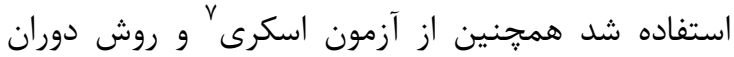

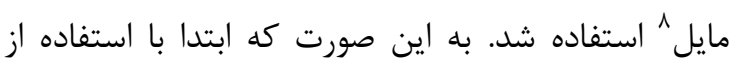
روش تحليل مولفه هاى اصلى عامل ها شناسايى شدند و

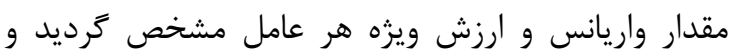

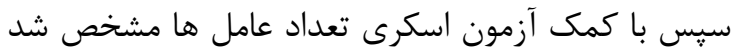
و با استفاده از روش دوران مايل هر سوال به يكى از عامل

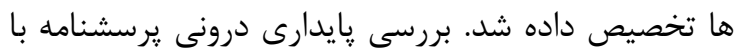
تعيين ضريب آلفاى كرونباخ به صورت كلى براى تمامى سوالات يرسشنامه و همجنين براى عامل هاى بدست

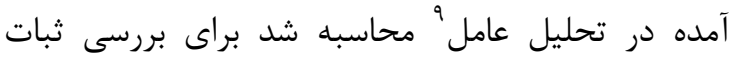

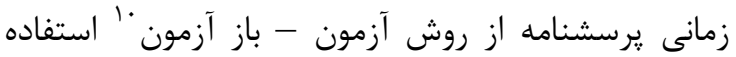

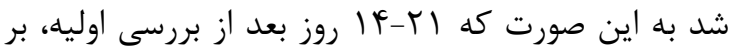

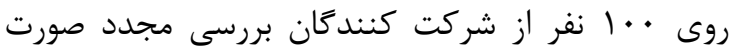
كرفت و مجدداً يرسشنامه براى آنها تكميل شد و و يس از ورود اطلاعات به نرم افزارSPSS16 ضريب همبستكى با استفاده از آزمون ICC' محاسبه شد. در منابع موجود جهت تعيين حجم نمونه براى اعتبار سنجى يرسشنامه ها براى هر سوال ب تا ها نفر به عنوان حجم نمونه در نظر گرفته شده است. كه در اين مطالعه بيشتر از اين تعداد و براى هر سوال r r نفر در نظر گرفته شده است و در كل

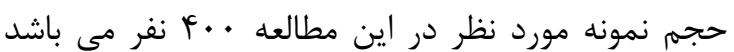

[rT]

معيار هاى ورود به مطالعه استخدام تمام وقت در يكى از واحد هاى تحت زوشش دانشعاه علوم پزشكى خراسان شمالى داشتن حداقل سه سال سابقه رانندگى با اتومبيل و تمايل براى تكميل پرسشنامه بوداين طرح در كميته اخلاق دانشكده بهداشت دانشعاه علوم يزشكى ايران تاييد

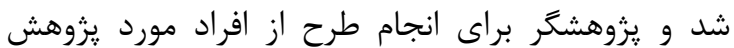
رضايت نامه شفاهى گرفت، يرسشنامه بدون نام و اطلاعات

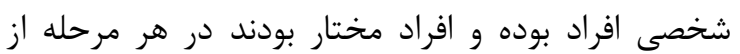

\section{6- KMO}

7 -Scree Plot

8 -Oblimin

9- Factor Analysis

10 -Reliability Test-Retest

11 -Intraclass Correlation Coefficient
״رسشنامه توسط مترجم از زبان انگليسى به فارسى ترجمه شده، سيس توسط مترجم مستقل از مترجم مرحله نخست فارسى به زبان انگليسى بركردانده شده و در نهايت

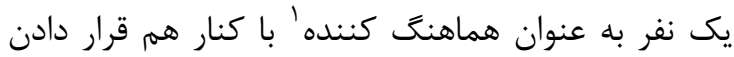
ترجمه هاى فارسى و انعليسى بدست آمده ويرايش فارسى يرسشنامه را تهيه نمود. يس از آماده شدن نسخه فارسى

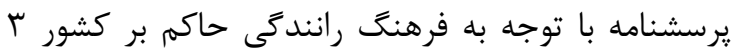
سوال توسط محقق به يرسشنامه اضافه گرديد. براى سنجش روايى محتوايى :يرسشنامه به 1 نفر از افراد خبره در حيطه روانشناسى و كارشناس راهنمايى و و روانى رانندگى به صورت جداكانه ارسال و از كارشناسان خواسته شد تا با توجه به اهداف طراحى يرسشنامه كه در دستور العمل زييوست شده به يرسشنامه درج شده است با مطالعه هر سوال به هر يك از سوالات بر اساس شكل و محتواى

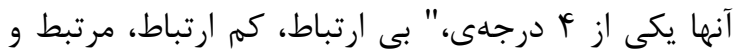

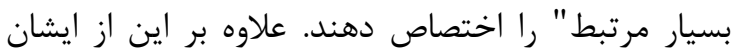
خواسته شده بود تا از ديدكاه خود شرايط يط ريا حالات ديخرى كه در كشور ما وجود دارد و جزو رفتارهاى رانندگى در زمينه انتقام در رانندگان ايران مى باشد ران عنوان نمايند. همجنين براى اطمينان از كويا بودن

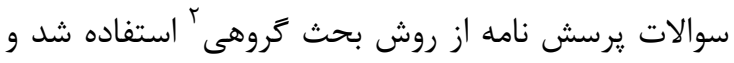

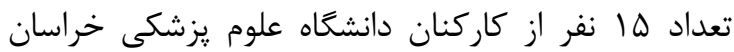
شمالى به جلسه بررسى يرسشنامه دعوت شدند در اين

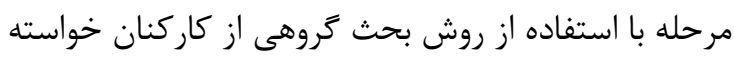

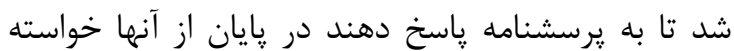

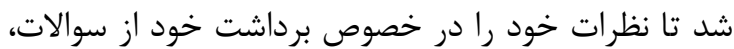

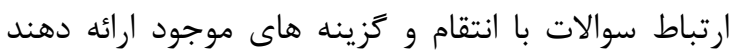
يس از ثبت و جمع بندى نظرات ايشان برخى سوالات اصلاح گرديد. بررسى اعتبار ساختارَّ به روش تحليل مولفه هاى اصلى

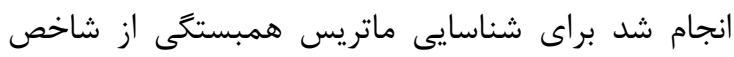

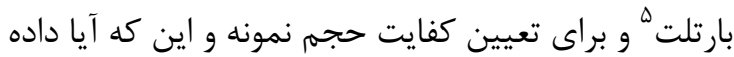
ها در حدى مطلوب هستند (به بتوان بر اساس آن عامل

1 -Coordinator

2 -Focus Group Discussion

3 -Construct Validity

4 -Principal Component Analysis

5 -Bartlett s Test 
شايعترين موقعيتى كه موجب انتقام مى شود سوال كا، كرفتن جاى يارك توسط وسيله نقليه ديخر مى باشد

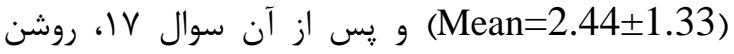

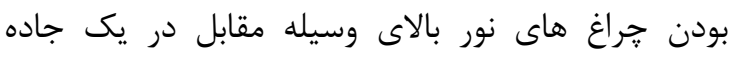
دوطرفه در شب مى باشد (Mean=2.34_1.4)

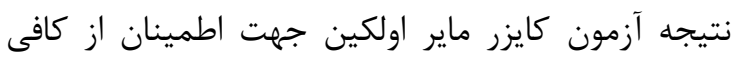

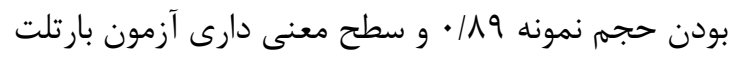

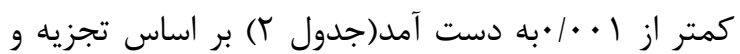

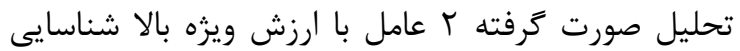

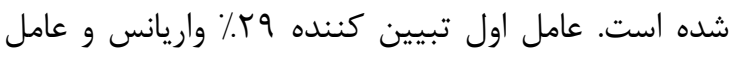

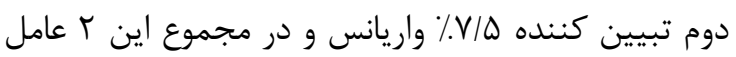

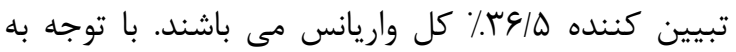

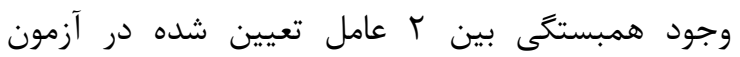

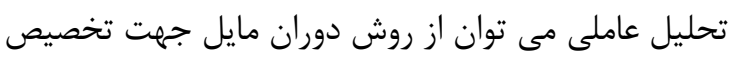

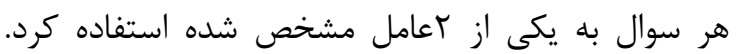

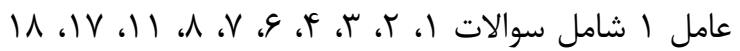

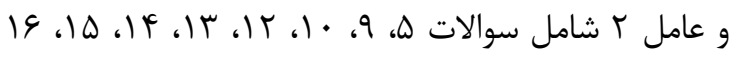

$$
\text { مى باشد (جدول rا، أ و ه) }
$$

تحقيق و به هر علتى از ادامٔ همكارى در اين تحقيق

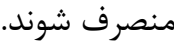

يافته ها

بر اساس يافته هاى بخش كيفى مطالعه به طور متوسط

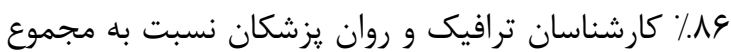

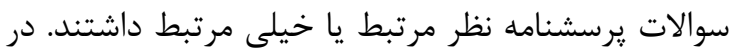

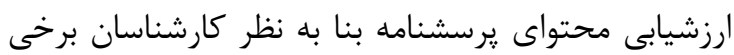

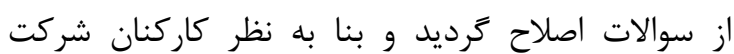
كننده در بحث در قسمت دموكرافيك قيمت وسيله نقليه و وضعيت تاهل به يرسشنامه اضافه شد و در ابتداى يرسشنامه و در متن معرفى يرسشنامه در خصوص تزينه هاى ارائه شده توضيح داده شد. در قسمت يافته هاى كمى ميانگين سن شركت كنندگان در مطالعه

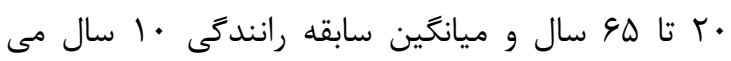

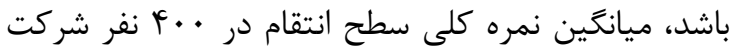

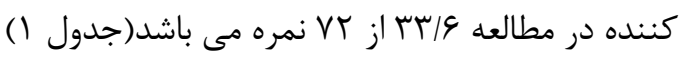

جدول ا: ويزَكيهاى دموكرافيك كاركنان دانشكاه علوم يزشكى خراسان شمالى شركت كننده در مطالعه

\begin{tabular}{|c|c|c|c|c|c|}
\hline فراوانى & متغير & & تعداد (درصد) & ت ت الغير & \\
\hline$(r q) \backslash 19$ & r تا ه سال & \multirow{7}{*}{ رابند } & $(\Delta) / \Lambda) r \cdot V$ & زير ·r ميليون & \multirow{6}{*}{ فيمت وسيله } \\
\hline$(T G \mid \Lambda) \mid F V$ & צ تا • ا سال & & س & اץ تا •r ميليون & \\
\hline$(Y \cdot / r) \wedge 1$ & 11 تا ها سال & & $(I T / T) F q$ & اس تا • أ ميليون & \\
\hline$(V / \Lambda) T^{\prime}$ & عا تا •r سال & & $(1 / \Delta) \varphi$ & أ تا • له ميليون & \\
\hline$(r) \mid r$ & ا r تا ه r سال & & $(\cdot \mid \Lambda)^{\mu}$ & اله تا •9 ميليون & \\
\hline$(T) \Lambda$ & عץ تا •r سال & & $(r) \mid r$ & بالاى او ميليون & \\
\hline$(1 / \Gamma) D$ & بالاى •r سال & & $(\Gamma \varphi / \Delta)) \cdot \varphi$ & ديِلم & \multirow[t]{5}{*}{ تحصيلات } \\
\hline$(r \Lambda / r) \| T$ & 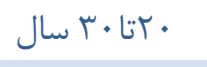 & \multirow{5}{*}{ سنى } & $(1 \Delta / \Delta) \& Y$ & كاردانى & \\
\hline$(\uparrow q / r) \mid q \vee$ & اس تا•ץ سال & & $\left(\mathcal{F}^{\leftarrow} / \Lambda\right) \backslash \vee \Delta$ & كارشناسى & \\
\hline$(\mid N / Y) V r$ & أباتا • لهال & & $(\varepsilon / T) \Gamma_{\Delta}$ & كارشناسى ارشد & \\
\hline$(f) \backslash \varepsilon$ & اهتا •ع سال & & 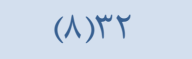 & دكترا & \\
\hline$(\cdot / r) 1$ & او تا•• سال & & $(1 \Gamma / \Delta) \Delta F^{F}$ & مجرد & \multirow{3}{*}{ تاهل } \\
\hline$(V \Delta / r) \mu \cdot 1$ & مرد & \multirow[t]{2}{*}{ جنس } & $(\Lambda \varepsilon)$ MFF & متاهل & \\
\hline$(Y F / \Lambda) 99$ & زن - ت ت & & $(\cdot / \Delta) r$ & مطلقه يا بيوه & \\
\hline
\end{tabular}


جدول r: شاخص كفايت نمونه و قابليت انجام دادن تحليل عاملى برسشنامه DVQ

\begin{tabular}{|c|c|c|}
\hline \multicolumn{2}{|c|}{$\cdot 119$} & آزمون كايزر ماير اولكين \\
\hline $1941 / 199$ & كاى اسكوئر & آزمون بارتلت \\
\hline IQT & درجه آزادى & \\
\hline كمتر از | ( . & سطح معنى داري & \\
\hline
\end{tabular}

جدول ז: نتايج تحليل عاملى 1/ سوال يرسشنامه DVQ و سوالات مشخص شده براى هر عامل

\begin{tabular}{|c|c|c|}
\hline \multicolumn{2}{|c|}{ Component } & \multirow[t]{2}{*}{ شماره سوال } \\
\hline عامل r & عامل 1 & \\
\hline$-\cdot|| c \mid$ & $\cdot|9 V|$ & 1 \\
\hline$-\cdot / 4 / T$ & $\cdot / \vee \Delta \Lambda$ & r \\
\hline$-\cdot / \cdot \Delta \Delta$ &.$/ V 19$ & r \\
\hline $.1 . .4$ &.$|9 V|$ & f \\
\hline . & . & $\Delta$ \\
\hline$\cdot|\cdot r|$ & .1949 & 9 \\
\hline - MFF & . MNT & V \\
\hline ./11r & $\cdot|48|$ & $\wedge$ \\
\hline.$/ 4 q 4$ &.$- / 1 V T$ & 9 \\
\hline . Aru & $\cdot / T V \Delta$ & 1. \\
\hline$\cdot / r \cdot r$ & . /frv & 11 \\
\hline$\cdot / \mathbb{\uparrow} \Delta \Delta$ &.$/ 19 V$ & ir \\
\hline . IGYV & $\cdot 1 \cdot V \Delta$ & Ir \\
\hline$\cdot \mid \Delta F V$ & $\cdot / r 9 \Delta$ & If \\
\hline ( & •/rqr & 10 \\
\hline$\cdot 1990$ & $-.1 \cdot 9$. & 19 \\
\hline$\cdot / r \Delta \omega$ & ./rq६ & IV \\
\hline.$/ 194$ & . MFET & 11 \\
\hline
\end{tabular}




\begin{tabular}{|c|c|c|c|}
\hline در صد واريانس تجمعى & درصد واريانس & عدد ويزه & عامل \\
\hline$r q / \cdot q$ & rq & D/THT & اول \\
\hline relgp & $V / \Delta$ & $1 / \pi \Delta$ & 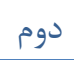 \\
\hline
\end{tabular}

\begin{tabular}{|c|c|c|c|}
\hline ضريب آلفاى كرنباخ & كويه هاى مرتبط طبق & تعداد & 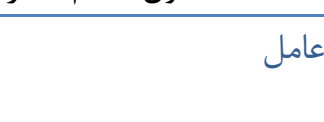 \\
\hline$\cdot / V \Lambda I$ & $|\Lambda-| V-||-\Lambda-V-\varphi-Y-r-r-1$ & 1. & شرايط عمومى \\
\hline$\cdot 18 \wedge \mathrm{V}$ & $\left|\varepsilon_{-}\right| \Delta_{-}\left|\varepsilon_{-}\right| r_{-}\left|r_{-}\right| \cdot-q-\Delta$ & $\wedge$ & شرايط مانع ديد و حركت \\
\hline
\end{tabular}

جدول \&: نتيجه آزمون Intraclass Correlation Coefficient و سنجش پايدارى درونى برسشنامه از طريق برآورد آلفاى كرونباخ

\begin{tabular}{|c|c|c|c|c|c|}
\hline آلفاى كرونباخ & سطح معنى دارى آزمون & حد بالا & حد پايين & $\begin{array}{l}\text { Intraclass } \\
\text { Correlation }\end{array}$ & 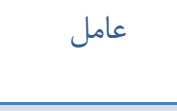 \\
\hline$\cdot / V \wedge \mid$ & 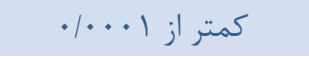 & .1911 & - MAt & - / ^९q & عامل 1 \\
\hline $.19 \wedge \mathrm{V}$ & كمتر از ا |... & - $|A T|$ &.$|9 \wedge|$ & $\cdot / V \Delta V$ & عامل r \\
\hline - IAT & كمتر از ا.|.|. & 194/. & $\cdot \mid A \vee \Lambda$ & $.19 \cdot 9$ & كل ״رسشنامه \\
\hline
\end{tabular}


جدول V: تعيين رابطه بين انتقام جويى و متغيرهاى دموگرافيك

\begin{tabular}{|c|c|c|c|}
\hline سطح معنى دارى & خطاى معيار & بتا & مدل \\
\hline كمتر از | • •. & $\mathrm{r} / \Lambda 1$ & $r q / T \Delta$ & Constant \\
\hline$\cdot 1 \cdot \cdot 1$ & .1 .94 & $-0 / T \& S$ & سن \\
\hline$\cdot 1 \cdot r$ & I/Tr & $-r / V \Delta$ & جنس \\
\hline$\cdot / 4 \& D$ & $\cdot / f \Delta \Delta$ & זسז/. & قيمت وسيله نقليه \\
\hline .1997 & - IFHF & $-\cdot 1 \cdot \cdot r$ & مدرك تحصيلى \\
\hline $.191 \mathrm{~V}$ & $1 / 01$ & .1109 & وضعيت تاهل \\
\hline.$/ 9 \wedge \mathrm{V}$ & $\cdot|\Delta V|$ & $\cdot 1 \cdot .9$ & سابقه رانددگى \\
\hline
\end{tabular}

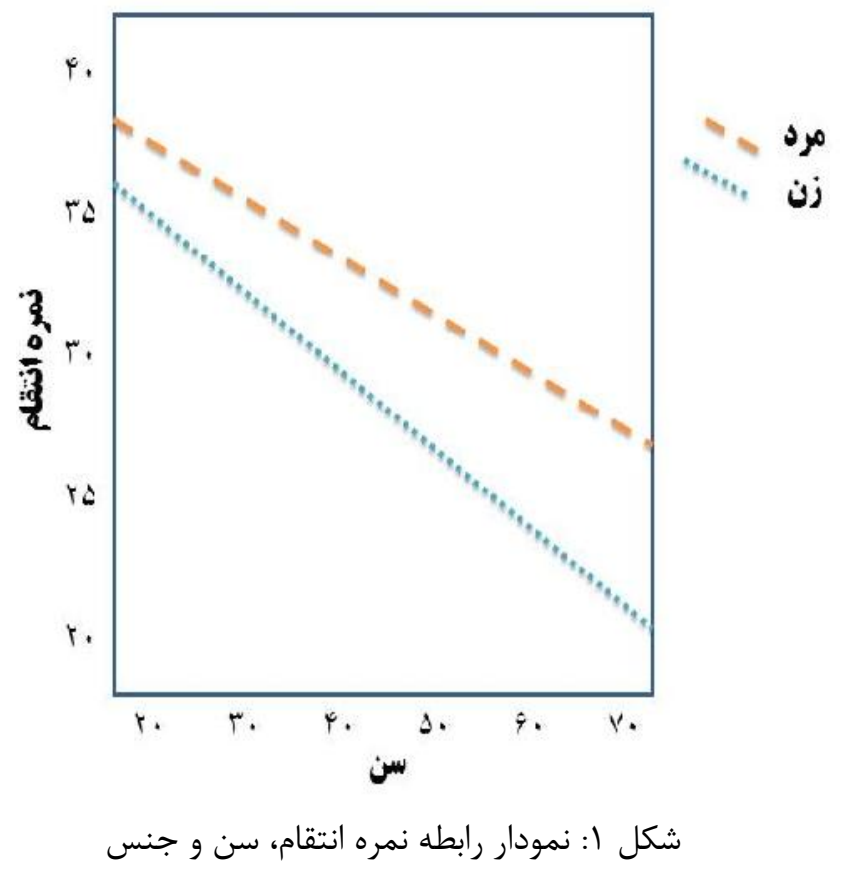


يايايى يرسشنامه ايشان از نظرات كارشناسان استفاده

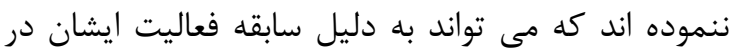

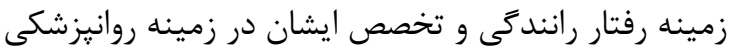

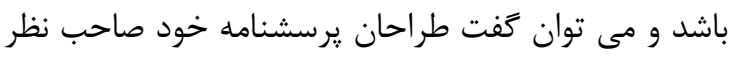
در زمينه رفتار رانندگى و انتقام در رانندگى مي بـ باشند.

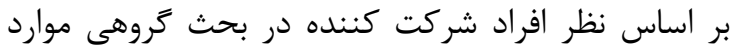
زير به يرسشنامه اضافه شد: در قسمت دموكرافيك قيمت ندر

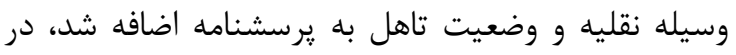
ابتداى يرسشنامه و در متن معرفى يرسشنامه در خصوص

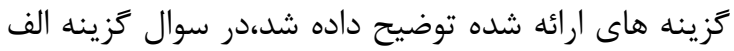

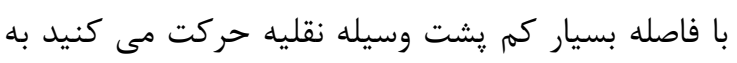
"يشت وسيله نقليه حركت مى كنيد " تغيير ييدا كرد. اما

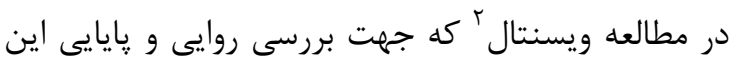
يرسشنامه انجام شد از اين روش استفاده نشده است

.[r)]

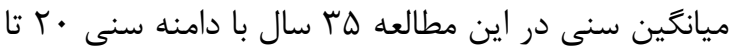
Q ه سال بدست آمد ولى در مطالعه ويسنتال ميانگين مطانين

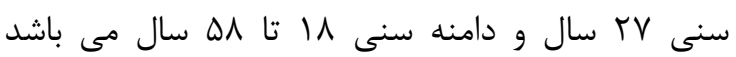

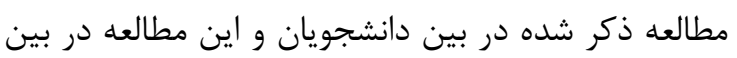

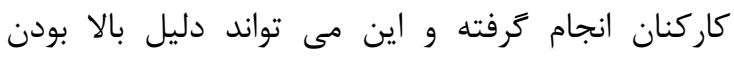
ميانگين سنى در اين مطالعه باشد يس إن از انجان انجام آزمون ركرسيون خطى קند كانه مشخص شد كه نمره كلى آنى

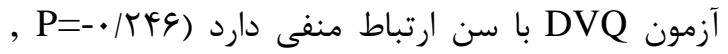

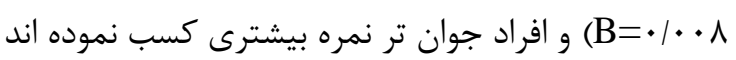

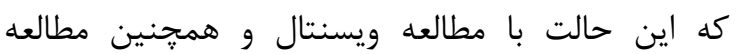

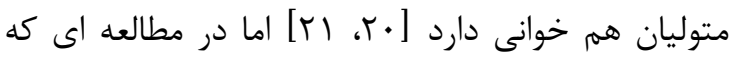

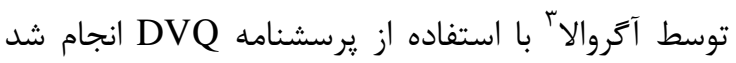

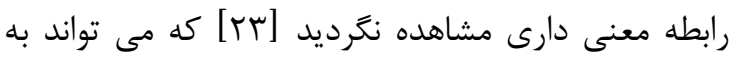
دليل يايين تر بودن ميانكَين سنى افراد شركت كننده

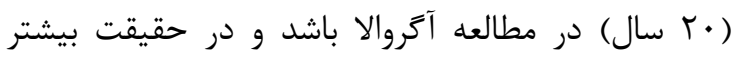

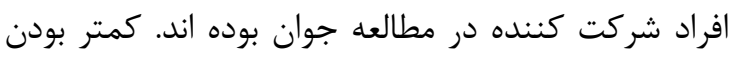
سطح انتقام جويى در افراد مسن مى تواند به دليل تجربه

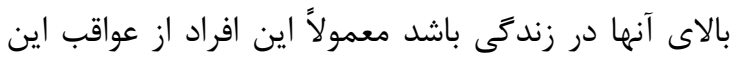
امر اطلاع دارند و به دليل اهميت بالاى سلامتى، خاند خانواده و آزادى كمتر به احساسات ناتهانى اجازه بروز مى دهند

\section{2 -Wiesenthal}

3 -Agerwala
با استفاده از آزمون ICC يايايى يرسشنامه 9.9 • • بر آورد

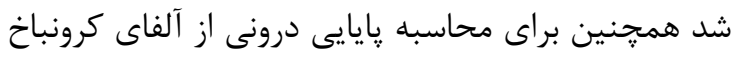

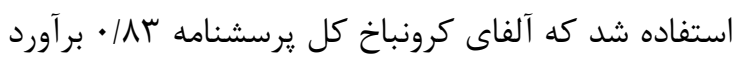

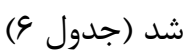
جهت بررسى رابطه بين متغيرهاى دموكرافيك و نمره

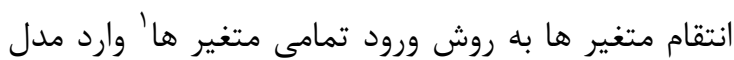
ركرسيون خطى خند گانه گرديدند، سطح انتقام با متغير

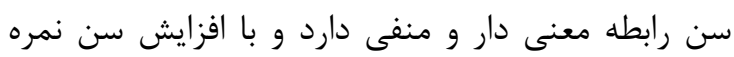
انتقام קايين مى آيد (P\& )

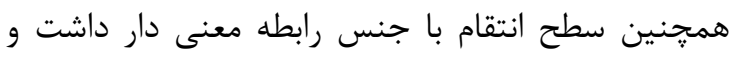

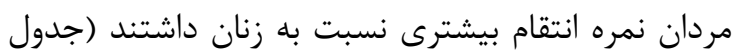

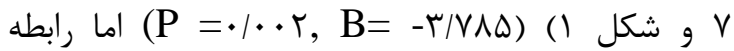
متغيرهاى قيمت وسيله نقليه، تحصيلات، وضعيت تاهل و سابقه رانندگى معنى دار نمى باشد وسيله نقليه تحصيل

به وجود آوردن معيارى براى سنجش استفاده از انتقام در

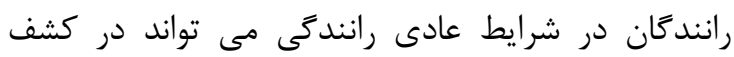

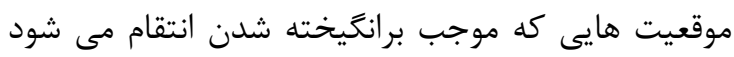
مفيد باشد. با توجه به اينكه در زمينه رفتار رانندگى در در

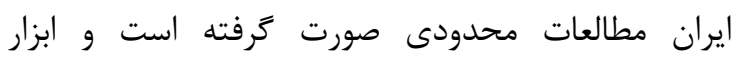

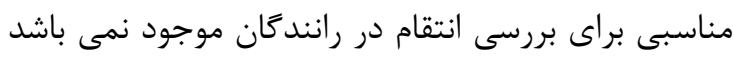
هدف از اين مطالعه تهيه يرسشنامه معتبر و زايا جهت سنجش انتقام در رانندكى مى باشد با توجه به اينكه

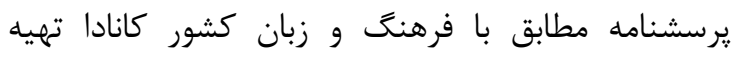

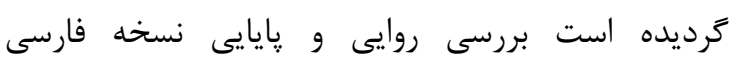
يرسشنامه با دو روش كمى و كيفى صورت كرفت.

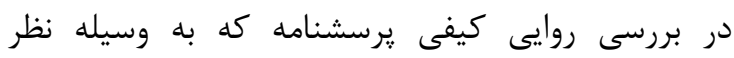

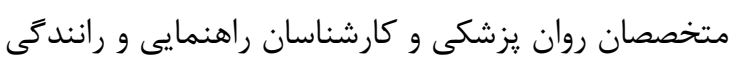
انجام شد ع./٪ كارشناسان راهنمايى و رانندگى و روان

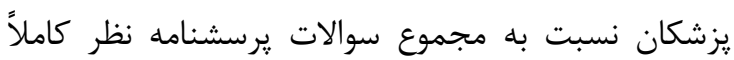

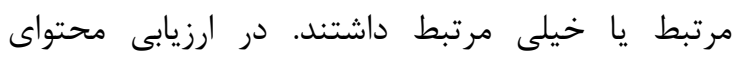
يرسشنامه بنا به نظر كارشناسان برخى از سوالات و جمله

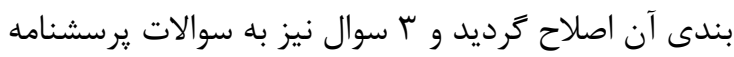
اضافه گرديد و هيج سوالى حذف نكرديد. در مطالعه انجام

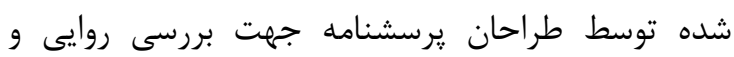

\section{1- Enter}


و براى كل קرسشنامه r/| • بدست آمد كه نشان دهنده

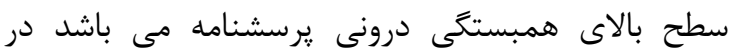

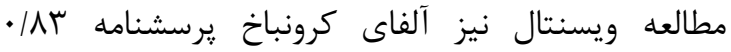

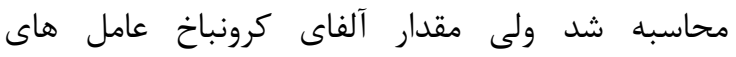

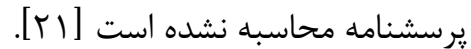

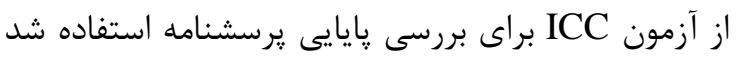

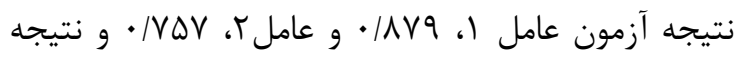

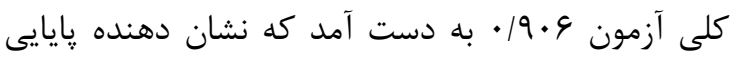
مطلوب يرسشنامه مى باشد ويسنتال در مطالعه بررسى بإنى

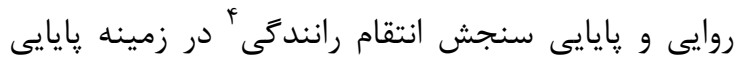

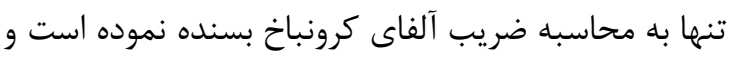
از روش ICC استفاده ننموده است. از نقاط قوت اين مطالعه مى توان به بالا بودن حجم نمونه نسبت به تعداد سوالات موجود اشاره كرد حد استاندارد

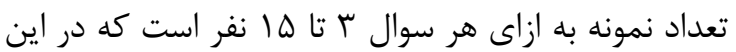
مطالعه به ازاى هر سوال r T نفر وارد مطالعه كرديد

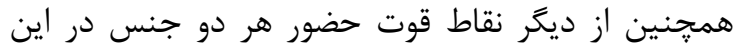

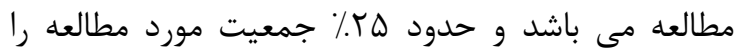
زنان تشكيل مى دادند كه با توجه به نسبت رانندكان زن به مرد در ايران قابل توجه است.

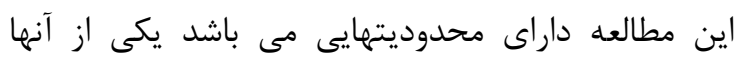

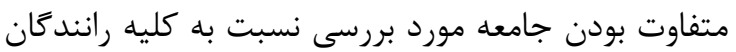
ايرانى مى باشد به دليل اينكه جمعيت مورد مطالعه

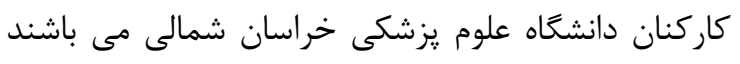

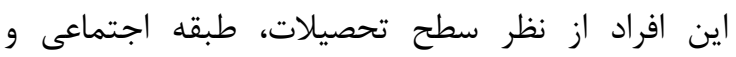
اقتصادى و سبك زندگى با رانندكان حاضر در جاده هاى ايران كه داراى فرهنَ متنوع زندكى و بالطبع فرهنَ

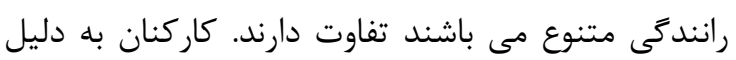
محدوديتهاى اعمال شده توسط شغلشان ممكن است از ساير افراد جامعه بيشتر محافظه كار باشند و اين محافظه

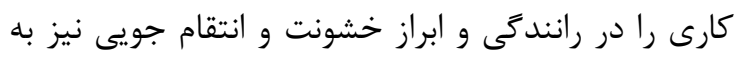

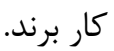

محدوديت ديكر شركت نكردن V نفر از شركت كنندكان

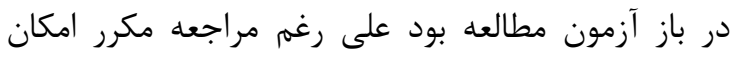
مصاحبه مجدد ميسر نكرديد محدوديت ديخر مطالعه به مأه

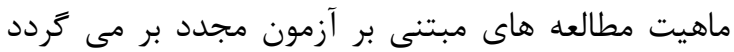

4 -DVQ
همجنين در آزمون ركرسيون خطى جند كانه جنس

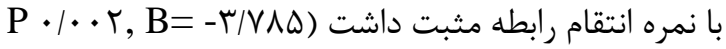
=) و مردان جوان بيشترين نمره انتقام جويى را كسب آنسان

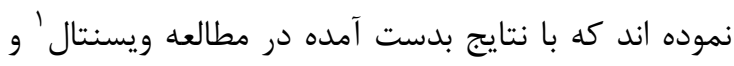

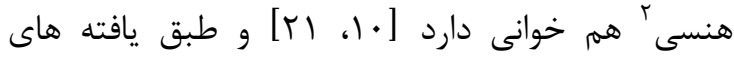
ايشان مردان جوان سطح يرخاشكرى و تهاجم بالاترى نسبت به ساير اعضاى جامعه دارند و واسانخ خشن ترى برى به

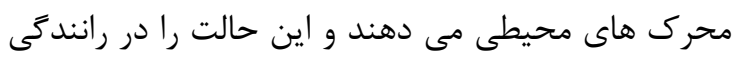
نيز بروز مى دهند و نكته جالب توجه اينجاست كه زنان

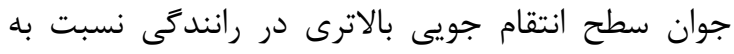

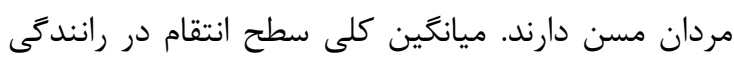

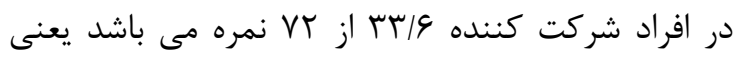

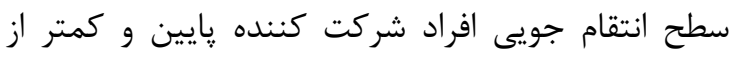

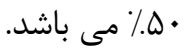

به منظور شناسايى عامل هاى اين يرسش نامه و بررسى بأى

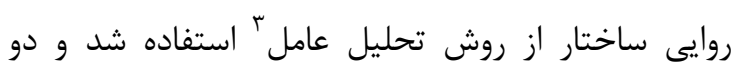

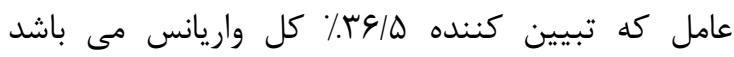
شناسايى كرديد و اين امر بيان كننده اعتبار داخلى دينى مطلوب براى اين يرسش نامه است در مطالعه ويسنتال نيز يرسشنامه به دو عامل تقسيم گرديده است با با اين تفاوت

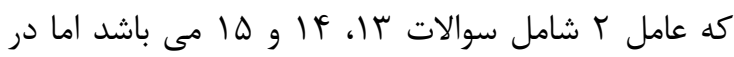
مطالعه حاضر علاوه بر اين، سوالات ه، 9، • •ا، با و و سوال

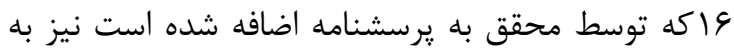

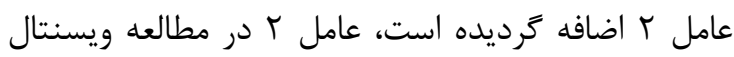

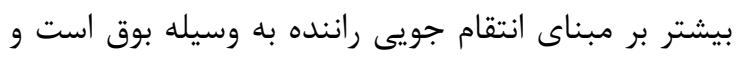

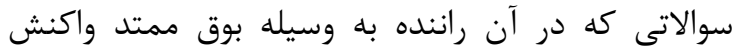

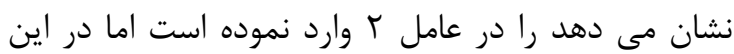

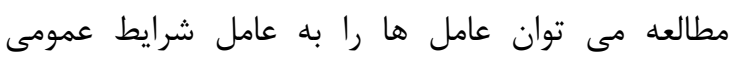
برانكيزنده انتقام و شرايطى كه مانع ديد و يا حركت راننده

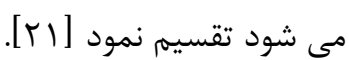

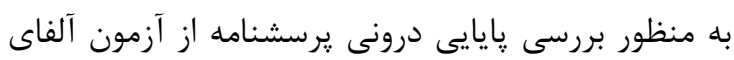

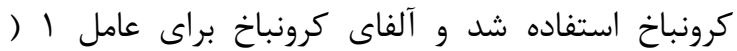

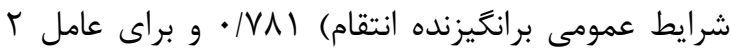

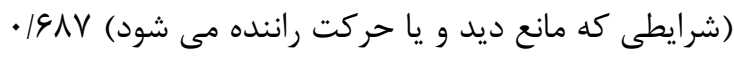

\section{1- Wiesenthal}

2- Hennessy

3 -Factor Analysis 
يكى از ويزگى هاى بازآزمون، انتقال اثر آزمون اول به به به

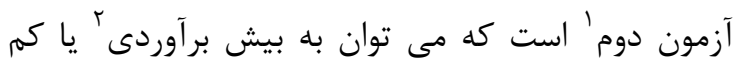

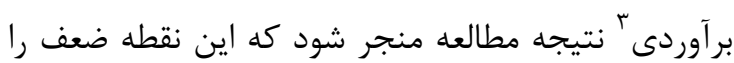

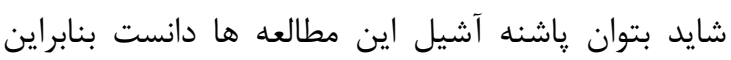

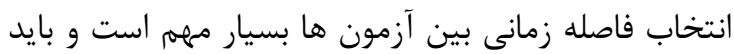
به اندازه اى باشد كه صفت مورد نظر تغيير نكند و با بال بررسى مطالعات مختلف و نظر كارشناسان فاصله مناسب

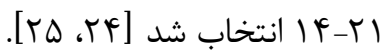

\section{نتيجه تيرى}

در مجموع اين مطالعه نشان داد كه نسخه فارسى

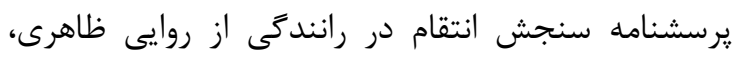

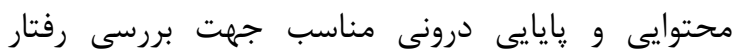

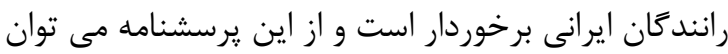

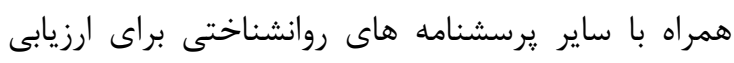

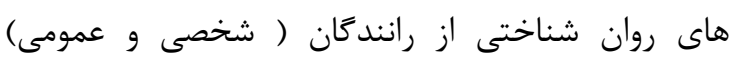

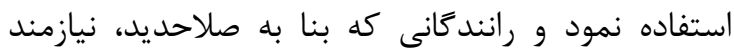

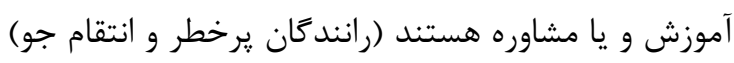
به صورت حضورى و يا غير حضورى در برنامه هاى

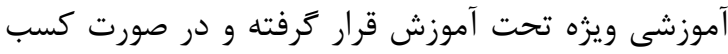

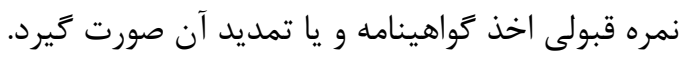

\section{تشكر و قدر دانى}

اين طرح بخشى از يايان نامه كارشناسى ارشد رشته

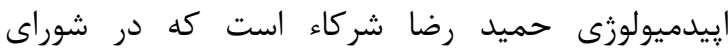
يزوهشى دانشكده بهداشت دانشخاه علوم يزشكى ايران باء

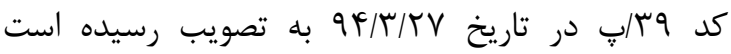

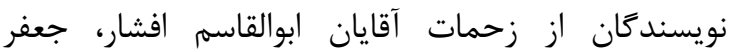
خدابنده، ياسر عباس زاده و مجيد افضلى جهت معان معرفى اندي

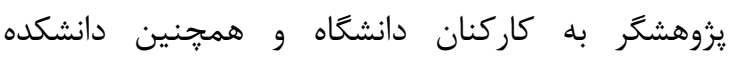
بهداشت دانشكاه علوم يزشكى ايران براى حمايت مادى از طرح سياس كذارى مى كنند. 


\section{References}

1. Global status report on road safety 2013 supporting a decade of action, Geneva, World Health Organization 2014; Available from: http://www.who.int/violence_injury_prevention/road_safety_status/2013/en./

2. Global burden of disease, Geneva, World HealthOrganization2008; Available from: http://www.who.int/healthinfo/global_burden_disease/estimates_regional/en/index.html.

3. Izanloo H, Ahmadi Jebelli M, Nazari S, Safavi N, Tashayoe HR, Majidi G, "et al", Studying the antibacterial effect of Polyamidoamine-G Dendrimer on some of the gram-negative and grampositive bacteria, Arak University of Medical Sciences Journal 2014;17(9):1-10[Persian]

4. Compare statistics of death and injuries in car accidents in 1391 and 1392, tehran: iranian legal medicine organization 1393 ;Available from: http://www.lmo.ir/index.aspx?siteid=1\&pageid=2370.

5. Kheirabadi GR, Bolhari J, Role of human factors in road accidents journal of research in behavioural sciences 1391;1(10):79-69[Persian].

6. Kopits E, Cropper ML, World Bank, Development Research GroupEnvironment and Infrastructure Traffic fatalities and economic growth Washington DC: World Bank, Development Research Group, Infrastructure and Environment 2003.

7. Nordfjærn T, Jørgensen S, Rundmo T, Cultural and socio-demographic predictors of car accident involvement in Norway, Ghana, Tanzania and Uganda, Safety science 2012;50(9):1862-72.

8. Rumar K, The role of perceptual and cognitive filters in observed behavior, Human behavior and traffic safety: Springer; 1985. p. 151-70.

9. EvansL, The dominant role of driver behavior in traffic safety, American Journal of Public Health, 1996;86(6):784-6.

10.Hennessy DA, Wiesenthal DL, Driving vengeance and willful violations: Clustering of problem driving attitudes, Journal of Applied Social Psychology 2005;35(1):61-79.

11.Haghayegh A, Oreizi HR, Relation of aggression types according to Karen Horney's Theory with negative and positive driving behaviors and accidents, Iranian J of Psychiatry and Clinical Psychology 2009;15:81-5.

12.Park C, Aggression: clinical- experimental, New York: Harper; 1999.

13.Deffenbacher JL, Deffenbacher DM, Lynch RS, Richards TL, Anger, aggression and risky behavior: a comparison of high and low anger drivers, Behaviour research and therapy, 2003;41(6):701-18.

14.Hennessy DA, Wiesenthal DL, Further validation of the driving vengeance questionnaire, Violence and Victims 2001;16(5):565-73.

15.Hennessy DA, The interaction of person and situation within the driving environment: Daily hassles, traffic congestion ,driver stress, aggression, vengeance and past performance: York University; 1999.

16. Hennessy DA, editor, The influence of driving vengeance on aggression and violence, Proceedings of the Canadian Multidisciplinary Road Safety Conference XI Halifax, Nova Scotia, Canada: Daltech Vehicle Safety Institute, Dalhousie University; 1999.

17.Deffenbacher JL, Lynch RS, Oetting ER, Swaim RC, The Driving Anger Expression Inventory: A measure of how people express their anger on the road, Behaviour research and therapy 2002;40(6):717-37.

18.Deffenbacher JL, GETTING ER, Lynch RS, Development of a driving anger scale, Psychological reports 1994;74(1):83-91.

19.Hamid Reza Oreyzi , Seyed Abbas Haghayegh, Psychometric properties of the Manchester Driving BehaviorQuestionnaire payesh 2010(1):21-8[Persian]

20.Motevalian SA, Asadi-Lari M, Rahimi H, Eftekhar M, editors, Validation of a persian version of motorcycle rider behavior questionnaire, Annals of Advances in Automotive Medicine/Annual Scientific Conference 2011: Association for the Advancement of Automotive Medicine.

21.Wiesenthal DL, Hennessy D, Gibson PM, The Driving Vengeance Questionnaire (DVQ): The development of a scale to measure deviant drivers' attitudes, Violence and Victims 2000;15(2):11536. 


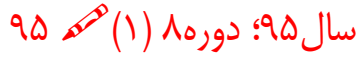

مجله دانشخاه علوم يزشكى خراسان شمالى

22.Munro BH, Statistical methods for health care research: Lippincott Williams \& Wilkins; 2005.

23. Agerwala SM, Votta A, Hogan B, Yannocone J, Samuels S, Chifriller S, Aggressive driving in young motorists, International Journal of Humanity and Social Sciences 2008;2(3):182-5.

24.Davis LL, Instrument review: Getting the most from a panel of experts, Applied nursing research, 1992;5(4):194-7.

25.Committee MSR, Faculty of Medical Sciences and Health Services of Iran, Questionnaire design principles in medicalstudies Tehran 2006;6. 


\title{
Validity and Reliability Assessment to Persian Version of Driving Vengeance Questionnaire (DVQ)
}

\author{
Shoraka $\mathrm{HR}^{I}$, Motevalian $S A^{2}$, Rajabzade $R^{I}$, Solaymani Dodaran $M^{2} *$
}

1MSc student in Epidemiology, Deputy of Public Health, Iran University of Medical Sciences , Tehran, Iran

2Associate Prof., Department of Epidemiology, Deputy of Public Health, Iran University

of Medical Sciences, Tehran, Iran

*Corresponding Author: Iran University of Medical Sciences, Tehran, Iran

Email:solaymani.m@iums.ac.ir

Abstract

Background \& objectives: In Iran, road traffic collisions are the first cause of disease burden. Driving is not means just applying technical skills to control the vehicle, but rather reflects the driver's classification of character. One of including variables related to driving is aggression. And causes a lot of dangers in driving. Based on our surveys through the world, questionnaire is the practical tool to assess driving behavior. The aim of this study is to assess the validity and reliability of $D V Q$ 's Persian version.

Materials and Methods: The 15-item DVQ was translated to Persian according to retranslation method. In the revised version, 3 new items were added and then completed by 400 staffs of North Khorasan University of Medical Sciences. Finally, we employed retranslation method and Cronbach's alpha coefficient to validity assessment.

Results: The mean age of the subjects was 35.88 years old. 301 Participants were male and 99 were female. We recognized in PCA Test 2 subscales which showed variance of $36.5 \%$ that their Cronbach's Alpha was between 0.68 to 0.78.ICC Test for 2 subscales and total questionnaire were from 0.75 to 0.87 . There were significant correlation among factors such as DVQ score, sex and age.

Conclusion: The results indicated that the 18-item Persian version of DVQ is a suitable criterion to recognize driver revenge-seeking behavior.

Key words: Driving vengeance Questionnaire, Validation Studies, Reliability

Received: 17 Jan 2016

Revised: 16 Feb 2016

Accepted: 3 May 2016 